But the very importance of the diagnosis which might thus be supposed to emerge from a disparity of the pupils in aneurysm served to quicken my sense of the fallacies which might arise from physiological and other causes of disparity apart from aneurysm. So far from becoming " convinced that inequality of the pupils ...... is in all cases due to implication of the sympathetic," it was not long before I became convinced of exactly the converse proposition. Case after case of aneurysm was observed in detail with regard to the pupils, and it was not long before I became convinced that slight and variable degrees of disparity (which were far from being rare) were almost of no account in the diagnosis, it being a not unusual experience to have the larger of the two pupils on the aneurysmal side, and variations taking place in this respect in the same case at different times. The valuable and exhaustive memoir of my friend $\mathrm{Dr}$. John Ogle was in this respect only unconvincing to me as it seemed to lay equal stress (or almost so) on dilatation and contraction of the pupil, the former being assumed to be (as in experiments) the result of irritation of the cilio-spinal nerves, the latter of pressure or destruction of them. It was difficult to disprove or to controvert the former mode of action from the theoretical point of view, and therefore I never attempted to do so; but as a matter of personal experience I have not succeeded in convincing myself that relative dilatation of the pupil is of any importance in the diagnosis of aneurysm; and myosis is only of importance when, as in my first case, it is manifest, permanent, and accompanied by such abnormalities of reaction as are referred to in detail in the article in Vol. Vr. of Clifford Allbutt's "System of Medicine," p. $400 \mathrm{et} s \in q$. If Dr. Wall and Dr. Walker will do me the favour to read carefully the cautionary statements in p. 404, or the summary of my experience in p. 406, they will, I think, entirely acquit me of having yielded to any such prejudice as they attribute to me. It would be easy to make this clearer by quoting more in detail, but as the work in question is very accessible to almost all your readers I forbear from burdening your space.

I am, Sirs, yours faithfully

Edinburgh, July 15th, 1902.

W. T. GaIRDNER.

\section{CIDER AND GOUT.}

To the Eators of $\mathrm{THE} \mathrm{LAN \textrm {ET }}$.

SrRs,--.Should the gouty drink cider? This is a question often put to medical men. The opinion of the authorities appears rather conflicting. I myself have prescribed cider in cases of atonic gout with great benefit. I am sure that you would do a great service to us if you would let us have the benefit of your opinion on the subject.

I am, Sirs, yours faithfully, Thomas Dobson, M.D. St. And.

Windermere, July 9th, 1902.

\section{DIPHTHERIA AND ITS TREATMENT AT COLCHESTER.}

To the Editors of THE LANCET.

SIRs, - As a year has now fully elapsed since the beginning of the epidemic of diphtheria in the borough of Colchester it may be advantageous to review this annus mirabilis so far as the disease in this locality is concerned in regard to its rise, progress, and decline, with any other circumstances of interest affecting it during the year. Commencing in the first week of May, 1901, it has continued to the present time and no intermediate month has been free from its presence. The number of notifications from the beginning of the year 1901 to its close was 287 and 43 were notified up to the end of May of that year, whilst 77 have been returned for the same period of this year, being 18 for January, February, March, and April, and 25 for May, 1901; and for this year, for January, February, March, and April, 62, and for May, 15, and only four for June, showing that the disease is now passing away. Like all epidemics it was small in amount, sporadic, and of a comparatively benign character at its beginning, but speedily showed a sudden large increase, virulent in type and located in well-defined special localities, in May and June, afterwards assuming in July and sub. sequent months a less virulent form though the numbers did not lessen till November and December. 23 deaths occurred in May, June, and July out of a
total of 137 notifications for that period in the borough.
111 patients were removed to the Infectious Hospital during these three months and 26 were treated at their own homes66 had antitoxin administered with 17 deaths, 45 were treated without antitoxin with three deaths, and 26 outside the Infectious Hospital, also with three deaths. Three of these deaths which occurred without antitoxin being used had the disease in a hopeless hæemorrhagic form on entering the hospital and others from organic disease either from the rapidity of the course of the malady or not being removed to the hospital soon enough for any remedy to restore the vital powers or to save life, and if antitoxin had been used in. such cases it would only have increased the death-roll of those who died after receiving that remedy. The total number of cases notified during the diphtheritic year commencing in May, 1901, and ending on April 30th, 1902, is $331-271$ being notified from May to December, 1901, and $6 z$ from January to April 30th, 1902, the deaths for the ejght months in 1901 being 34 and those of the four months of 1902 eight, giving a total of 42 and a death-rate of 12.69 for the entire period.

There is probably no disease, taking it in all its phases. requiring more discrimination in its diagnosis or discretion in its treatment than this, the diseases affecting the throat being very numerous and difficult to differentiate, especially in their first stage-the time most important, especially in diphtheria, in securing the best chance of success in preventing a fatal result and a long convalescence. It seems also only natural that diphtheria should be at once attacked at its point of origin and the system of cure which ignores this fact is not based on true physiological principles. Remove the cause and the effect ceases, and this can easily be done at the onset and the result is everything that can be desired in a speedy removal of the dangerous poison and a short convalescence. 'The cilia or brushing apparatus with which the mucous membrane of the throat and back part of the mouth is lined are soon clogged with dead matter and bacteria and their action arrested, thereby furnishing a fitting nest for the batching of the toxins which enter the system and which give rise to all the evil consequences of the disease. The first line of attack is therefore to be put in force at once by clearing the throat of these lethal products and enabling these minute organs free play in resuming their natural function of keeping the throat clean. So essential are these minute organs in the animal economy and their vitality is so great that they continue in action after removal from the throat and even for three or four days after death do not lose their power of movement. It is therefore a most important point in the treatment of the disease to restore their function at the soonest possible time and thus allow a means of exit to their imprisoned poisons. This means of cure also lessens the chance of infection being conveyed to others, for whilst only one case of infection occurred during the 17 years previously to 1901 at the infectious hospital, seven nurses and one ward attendant were attacked by the malady during the present epidemic and the antitoxin treatment does not prevent the disease spreading to others after the patient is said to be cured.

It appears derogatory to the science and practice of medicine and surgery that it should be imperative as some practitioners hold that there should be only one system of cure to a specific form of disease, that there should be no progress in the healing art, and that the most ignorant and the most experienced should be bound by a hard-andfast rule to pursue a course of treatment which frequent]y entails more misery on the sufferer than the original disease itself could produce. There are many mild cases of diphtheria-indeed, the majority are such-that require little treatment and some that defy all human skill, as there are cases of malignant scarlet fever and like diseases that exhibit the same tendency and are extremely fatal in the young. After July 2nd, 1901, the disease was generally of a mild form and 26 cases were admitted into the hospital from that date without a single death up to the 19th and since then only occasional cases of a virulent character occurred, the cases both inside and outside the hospital being of the same description. It is a well-known law in medical science that if one disease is already in the system another as a rule is denied admittance, or if introduced it action is greatly modified or suspended till the first has run its course. Cases of scarlet fever occurred in this way ant in many cases were fatal after the diphtheria.

On the other hand, some children were admitted with diphtheria and in two or three days atter admission chickenpox made its appearance and though one of them had a verg 
bad throat all recovered. Dr. Jenner 100 years ago was cognisant of this fact and it is interesting to find in his biography that he was foiled in his attempt to vaccinate some patients in Colchester owing to this law. His biographer relates that "on the 15th of April, 1800, His Royal Highness the Duke of York sent a message to Dr. Jenner to request him to go to Colchester to vaccinate the 85th Regiment. He was under the necessity of waiting a considerable time before he could communicate the disease to anyone. He found the whole of the regiment, together with the women and children, labouring under the itch. He commenced his inoculations but they all proved unsuccessful. On the 2nd of May he found that one child had taken the cow-pox and he adds that all the men are cured of the itch and in two days will be washed and fit for vaccination. These anticipations proved rather premature, for he observed on the 13th of May that he could not succeed in communicating the true cow-pox to those whose constitutions had been under the influence of the itch." His biographer states: "It appears to me of moment to allude to these assurances, because they afford very convincing proofs of the truth of a doctrine which Jenner subsequently adopted and invariably maintained to the last hour of his life-namely, that any cutaneous disease, however slight in appearance, was capable of interfering with the regular course of cow-pox and from preventing it from exercising its full protecting influence. Though Dr. Jenner could not himself undertake to vaccinate the regiment at Colchester he went twice to that place to inspect the progress of the practice." It would be of immense value to mankind if such a remedy were found to give immunity from diphtheria and the same course could be pursued and with the same certainty of success as vaccination gives in small-pox. Antitoxin is said to give immunity for three weeks, just as we may surmise that any other disease, such as chicken-pox, might have the same effect. As a prophylactic the remedy of antitoxin in mild cases is often worse than the disease and even as an adjunct to the topical treatment in producing tetanus, severe urticaria, and other serious maladies it cannot be pronounced as altogether safe. Surely the resources of the human mind have not yet arrived at that state of sterility to preclude the idea of such a remedy being discovered in our own age, and it is even possible that another Jenner may arise to find out a safe, speedy, and pleasant cure for this dreaded disease in anticipating its coming and neutralising its effects and lessening its mortality.

The disease followed the usual course of an ordinary epidemic, and though a bacteriological office was instituted in September and it was stated that the disease would be extirpated in six weeks yet it did not have any marked decline till last month. An isolation home was also inaugurated and patients who had been treated with antitoxin in the infectious hospital, but whose throats were still infected with bacteria, were placed there till their throats were free from these germs. These modes of checking the disease have been an enormous expense to the borough and cannot be considered of a therapeutic value equal to what has been claimed for them or the results have shown. The copious showers which have fallen during the past three months have been the chief cause of the decline of the disease and have been far more potent in their effects in checking it than any number of artificial schemes instituted for its suppression. The science and art of surgery have no doubt advanced greatly during the latter half of last century and its boundaries have been greatly extended by the painstaking and elaborate schemes pursued in investigating the secret causes which produce and influence disease, zet the rapid progress may tempt some to cling to a theory which more extended inquiry and research may prove to be fallacious, and thus they lead them to worship an idolum specus as a true divinity. Antitoxin has in this way been held up as a therapeutical save-all. It is needless to say that its use given indiscriminately traverses Jenner's great law that the protective principle must be introduced into the system before the disease for which it is used breaks out.

Though, then, great advances have been made in the profession, yet it does not appear that the ordinary life of the professional medical man has much improved. In Pearson's "Life of Hey," who practised 100 years ago, the author throws some light on the way the world went at that time. He says " that there are scarcely any opinions or modes of treatment that do not lie open to censure and animadversion, no method of managing a disease of which it mav not be pronounced if unsuccessful: "Had this been done or that left undone the issue would have been more fortunate.' Hence a man disposed to detract from the merit, to disparage the qualifications of his professional brethren, to impute mistake or incompetence to them, may easily find specious pretences for arraigning their conduct and a willing audier.ce to listen to his ignorant, interested, or malicious insinuations." Civilisation, it is said, advances in a circle and it may be that the moral powers lag in the race in contrast with the intellectual.

I am, Sirs, yours faithfully,

Colchester, July 1st, $1902 . \quad$ GEORGE BRowr, M.D. Glasg.

\section{PERITYPHLITIS.}

To the Editors of THE LANCET.

SrRs,-Educated at Guy's Hospital before 1886 and familiar from my student days with the starting-point of perityphlitis, it has seemed to me that one meets with more cases in the post-mortem room since operative treatment has become so common. The few fatal cases seen by so careful an observer as Sir William Gairdner in the days before the disease was considered to be mainly surgical supports this view. By making such a suggestion one does not intend to reflect upon the value of surgery in perityphlitis, but the dogmas of surgery must be the result of experience, and in gaining experience it sometimes happens that the few have to suffer for the many. Removal of the appendix in the quiescent stage is obviously a simple matter in the hands of an able surgeon like Sir Frederick Treves, but too often probably an operation in the acute stage, as suggested by Hilton Fagge, who had "twice seen an exploratory operation performed in suppurative peritonitis starting from ulceration of the vermiform appendix," 1 may remove "the last chance of life," especially when the peritonitis is not general and adhesions are commencing to localise the inflammation. If surgery only for a short period in the past increased the fatality of perityphlitis one can understand how the increased opportunities thus afforded for study may have appeared almost to have led to the discovery of a new disease.

It may be added that some surgeons, at least at Guy's Hospital, were familiar before 1886 with the morbid anatomy of perityphlitis. I remember a clinical lecture given by Sir H. Greenway Howse upon perityphlitis two or three years before that date in which the origin of the trouble in the appendix was mentioned and the rarity of foreign bodies emphasised. The lecturer told us how when staying in a cherry-growing district in France, where the abundant swallowing of cherry-stones was seen by their number in the fæces of peasants which were left in the fields, he had been unable to find any indication that this habit of swallowing the stones led to perityphlitis being more common there than elsewhere.

I am, Sirs, yours faithfully,

Clifton, Bristol, July 12th, $1902 . \quad$ THEODORE Fisher.

\section{To the Editors of THE LANCET.}

SIRs,-I hardly think that it is worth while writing and complaining about Sir Frederick Treves describing the above as a new or recent disease, for by reading his lecture closely one discovers that he gives a long history to it. Perhaps on the whole Guy's men have been more alive to the important part which the appendix has played in the disease than men of other schools on account of the teaching of Addison, Wilks, and Fagge. What, I take, Sir Frederick Treves seeks to bring out in his lecture is that surgically it is a new disease, or rather that modern surgery has given a new and practical importance to it. This, I think, is no doubt true. I was at Guy's Hospital some 25 years ago and during my stay there of six years I never saw a case of appendicitis operated upon, although. I believe, very soon indeed after my leaving Mr. Charters Symonds operated successfully upon a case under the care of the late Dr. Mahomed.

What is important to remember still is, as Sir Frederick Treves insists upon, that the vast majority of cases recover ; and again, as Sir W. R. Gowers points out, the severest attack is commonly the curative one. Personally I have had two attacks; to describe them would take up too much 